Martin Boros - Matej Kucera - Andrej Velas - Jan Valouch

\title{
POSSIBILITIES FOR EXPERIMENTAL TESTING OF ALARM TRANSMISSION SISTEMS
}

In the current digital era, information is a basis of some systems. In the area of information, great emphasis is also placed on its security and possibilities of use. The basis of the alarm transmission system is information about the protected object, which is transmitted to the remote center of the alarm transmission system.

Operators of alarm transmission system centers should be obliged to carry out regular testing of the availability of individual transmission networks. At present, there is a trend that those tests are carried out by telephone calls between the two technicians and the time of transmission of information is measured utilizing a stopwatch. To automate this process, a test facility has been created that can simulate and record the intrusion of a protected object. Initial experimental tests have ascertained whether it is possible, with the test equipment, to generate the data necessary to assess the reliability of alarm transmission systems.

Keywords: test facility, alarm transmission system, information, protected object, alarm transmission system center

\section{Introduction}

An object protection system can be understood as a thought-out arrangement of security features, measures and their properties that all together create a sense of security. These elements could be divided into four basic groups: passive protection elements, active protection elements, physical protection elements and regimeorganizational measures. The passive protection elements include mechanical barrier systems, usually supplemented with apertures. The alarm transmission system, together with the electrical alarm system, video surveillance system, fire alarm system, access control system and others, belong to the group of alarm systems as active protection elements. Given the name of the group, one can say that the basis of an alarm system is an alarm, which can be defined as a warning of the presence of a danger to life, property or environment [1-2].

An alarm transmission system is defined, according to technical regulations, as an alarm transmission device and a network used to transmit the status information of one or more alarm systems to one or more alarm devices of one or more alarm reception centers. In addition to the basic and specific requirements for alarm systems, the technical standards also include the concept of an alarm transmission system monitoring center, which is understood as a continuous service center in which the condition and functionality of one or more alarm transmission systems are monitored. The monitoring center of the alarm transmission system is comprehensively addressed by a separate technical standard which, in addition to the functional ones, includes the design requirements, as well.

Given the nature and importance of the alarm transmission system, one could divide it into three basic parts, which are the transmitting device in the protected building, the transmission path and the receiving device in the monitoring center. The configuration and setting of the alarm transmission system shall, depending on the technical standards, correspond to the logical continuity shown in the block diagram in Figure 1.

There are several definitions in literature of the system reliability, depending on the area in which the system is located. The basic definition, based on technical standards, defines reliability as the property (ability) of a product or system to perform the desired function within a specified time, while maintaining operating parameters. Reliability can be expressed by using one of its basic parameters: no-failure operation, machine life, reparability, machine availability [3].

Based on categorization of the backup transmission paths use, one assumes that the transmission paths designated SP1-6 do not use the backup transmission path. The DP1-4 paths use an alternative, backup path, depending on the capabilities of the attached, protected object.

To increase efficiency and reliability of an alarm transmission system, the connection of the object via a backup transmission path is used in practice, which is used in the case of a primary malfunction. Due to this possibility of connection of objects, the technical standard divides them into two basic groups, whose transfer times

\footnotetext{
Martin Boros ${ }^{1, *}$, Matej Kucera ${ }^{2}$, Andrej Velas ${ }^{1}$, Jan Valouch $^{3}$

${ }^{1}$ Department of Security Management, Faculty of Security Engineering, University of Zilina, Slovakia

${ }^{2}$ Department of Measurement and Applied Electrical Engineering, Faculty of Electrical Engineering and Information Technology,

University of Zilina, Slovakia

${ }^{3}$ Department of Security Engineering, Faculty of Applied Informatics, Tomas Bata University in Zlin, Czech Republic

*E-mail of corresponding author: martin.boros@fbi.uniza.sk
} 


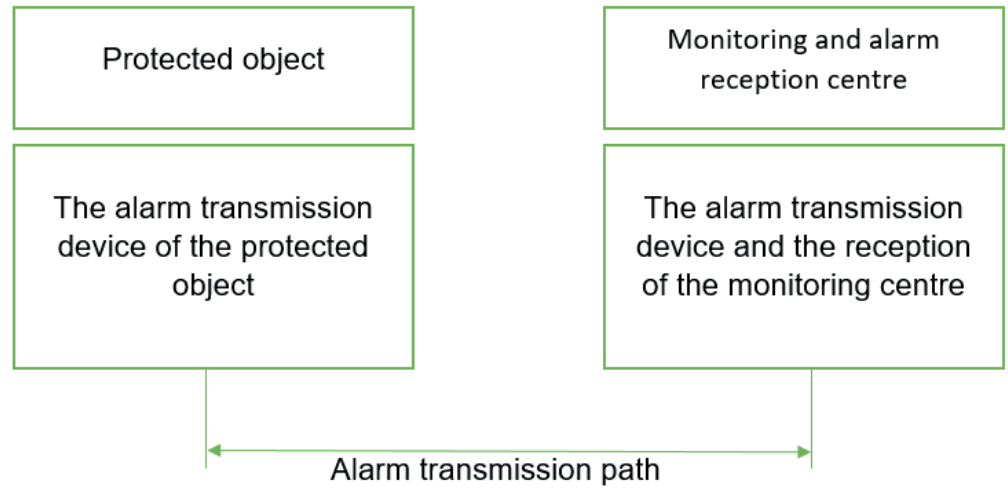

Figure 1 Block diagram of the alarm transmission system

Table 1 Maximum message transmission time and system availability values for weekly and annual periods

\begin{tabular}{ccccccccccc}
\hline & SP1 & SP2 & SP3 & SP4 & SP5 & SP6 & DP1 & DP2 & DP3 & DP4 \\
\hline $\begin{array}{c}\text { Maximum transmission time } \\
\text { allowed [s] }\end{array}$ & 480 & 120 & 60 & 60 & 30 & 30 & 120 & 60 & 60 & 30 \\
Weekly period [\%] & $\mathrm{V}$ & $\mathrm{V}$ & $\mathrm{V}$ & 97.0 & 99.0 & 99.8 & $\mathrm{~V}$ & 99.0 & 99.8 & 99.8 \\
Annual period [\%] & $\mathrm{V}$ & $\mathrm{V}$ & 97.0 & 99.0 & 99.5 & 99.9 & $\mathrm{~V}$ & 99.5 & 99.9 & 99.9 \\
& & \multicolumn{7}{c}{$\mathrm{V}=$ optional } & &
\end{tabular}

could be divided according to the degree of risk. The technical standards for alarm transmission systems define four basic levels of risk in terms of the importance of the connected object, where level 1 represents a low risk and level 4 a high risk. From the above and using Table 1, one can state the following classification:

- Level 1: categories SP1, DP1,

- Level 2: categories SP2, DP2,

- Level 3: categories SP3, SP4, DP3,

- Level 4: categories SP5, SP6, DP4.

Performance of the alarm transmission system, one of the main indicators of system reliability, is influenced by several indicators aimed at the signal transmission. Those indicators could include, for example, message transmission time, connection/connection monitoring, monitoring of the individual parts of the alarm transmission system functioning [4].

The alarm transfer time is determined by the arithmetic mean of the message transfer time and 95 percens of the message transfer time measurement. By this combination, one gets the maximum allowed time of the message transmission from the protected object to the alarm transmission system center. The maximum allowable message transfer time values are shown in Table 1 . The message transfer time is the period measured from the moment when the information appears on the interface of the transmitting device located in the protected area to the time it is recorded at the interface of the receiving device located in the alarm transmission center system. Any message transfer time exceeding the maximum allowed message transfer time, specified in Table 1 , shall be defined as a transmission system failure.
Reliability of the alarm transmission system is a fundamental probability indicator affecting the cumulative probability of an object protection system.

The basic indicator of reliability, in terms of alarm transmission systems, is their availability. Availability is the percentage of time that the system or parts of it operate according to requirements of the technical standards. One could say that it is an expression of the time during which the alarm transmission system can transmit information from the protected object to the alarm transmission system center without disturbing or devaluing it. The technical standards and the literature refer to the weekly and yearly availability of the alarm transmission system, as shown in Table 1. The calculation and/or expression of availability can be done using formulas to calculate the weekly, monthly and yearly availability values of the alarm transmission system level of table 1 for each class.

Regular tests of connection of the protected object and the alarm system monitoring center should be carried out to obtain the data necessary for expressing availability. Tests of this type are carried out by operators of the alarm system monitoring center every week and are particularly useful for their personal needs. For scientific research, it is necessary to carry out the comprehensive tests covering several parts of the object protection system such as the electrical security system, the camera system and the like [5-6].

\section{Methodology}

Within the scope and focus of the paper, the focus was set only on experimental testing of the alarm transmission 


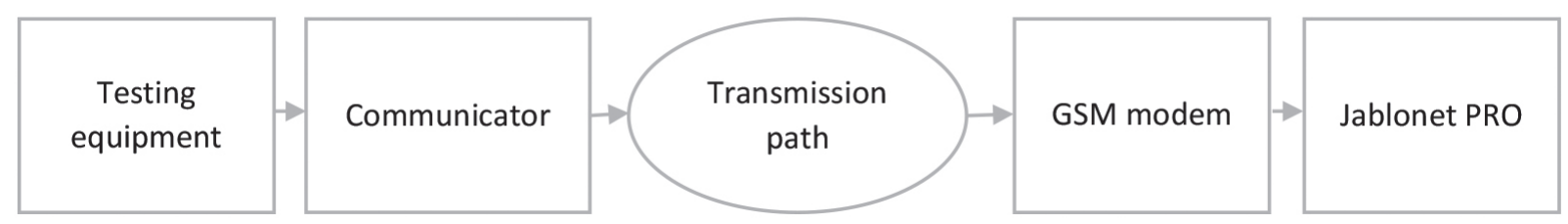

Figure 2 Block diagram of transmission path connection during experimental testing

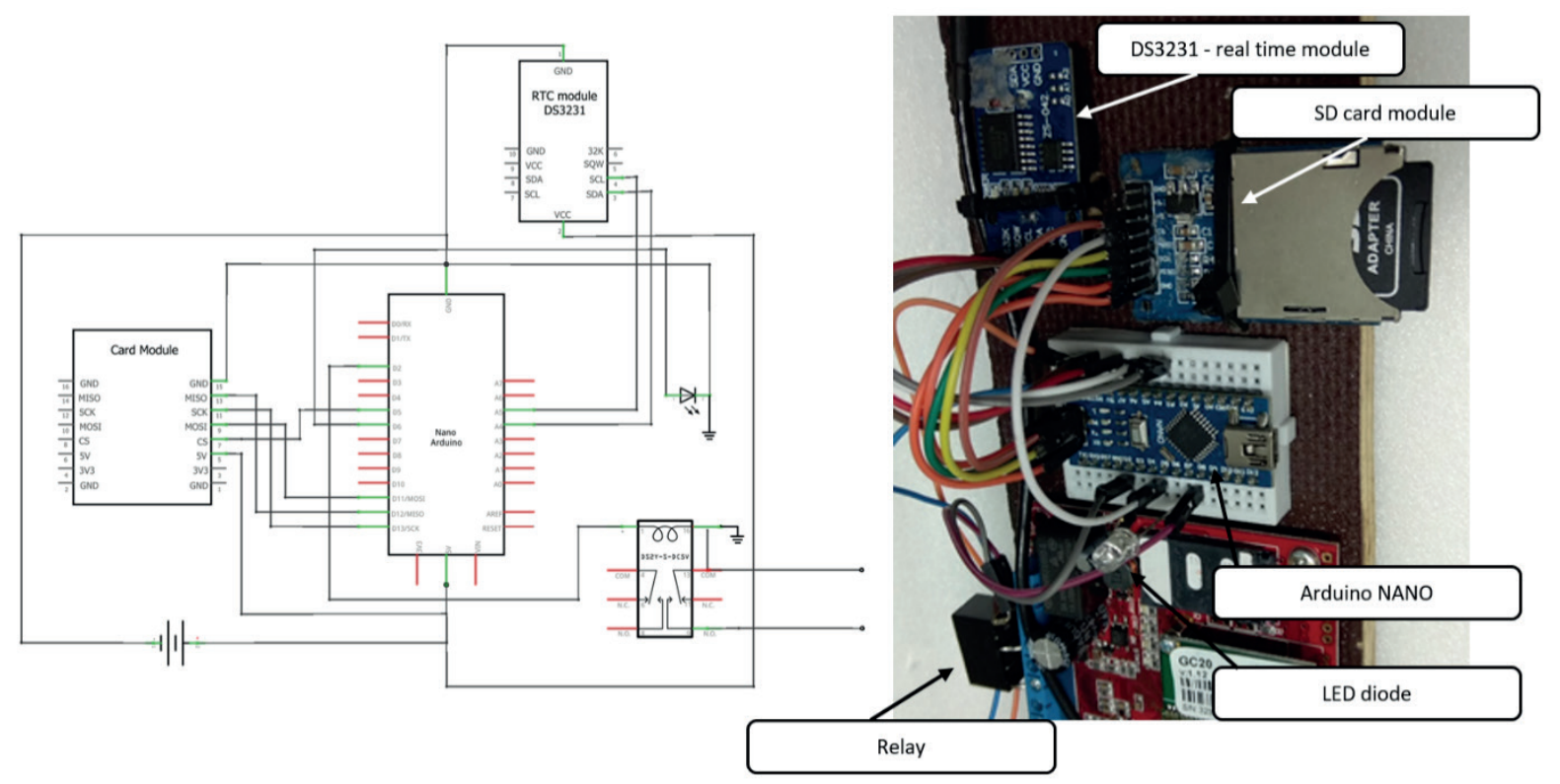

Figure 3 Wiring diagram of the test device together with an example of real connection of the test equipment

systems. The experiment, or the method of experiment, has a key position among the methods of quantitative research because it is the only one able to prove or confirm causal consequences, respectively. Its implementation is mostly used to verify experience and to confirm or refute scientific questions or hypotheses. In the experiment, one encounters independent variables that can be modified and changed depending on the requirements to make their impact on results clear.

Through the experimental testing of the alarm transmission system, the scientific activities of the Faculty of Security Engineering focus on creating a database of data designed to assess the reliability of the alarm transmission system. The focus was placed on the transmission information time, from the protected object to the alarm transmission system center. In conducting the experimental tests, the unified connection of the alarm transmission path was used, block diagram of which is shown in Figure 2. The experimental testing was preceded by the creation of a test facility that can be considered as an innovative way of obtaining the data needed to evaluate the object protection system.

The test facility is built using components on the open-source Arduino platform. Testing equipment during experimental testing by connecting components and they aimed to determine the real functionality and possibility of use in practice. Therefore, at this stage of testing, the tester did not have any type of box. The test equipment is designed and constructed to be compatible with transmission equipment operating in different transmission networks. As can be seen in Figure 2, the GSM transmission network was used during the experimental tests [7].

The Arduino platform was chosen because of its extensibility and the considerable amount of free information and knowledge from various online forums. The test device is based on a programmable Arduino NANO motherboard, which is adapted to be used in a plug-in, connection box without soldering. The testing device also includes a real-time module and an SD card slot on which each change of the system status is recorded, an LED for optical status change indication. The block diagram of the test device is shown in Figure 3.

Communicator GC-20A is designed for installation in smaller buildings such as houses, cottages where transmission of many messages is not expected. The communicator uses the Contact ID (CID) encryption to transmit information. The CID is a digital communication format that contains fifteen characters that together form a description of the event with the identification of the location of the alarm in the protected object. The communicator can create a backup transmission path in the form of SMS messages, as GPRS transmission is used as the primary one. The GSM Wireless Airlink Fastrack Xtend EDGE FXT009 GSM modem is a fully programmable GSM modem that can be extended with GPS modules. The modem can be connected via traditional RS232 serial 
Table 2 Measured values of experimental testing

\begin{tabular}{|c|c|c|c|}
\hline & Property - 1 & Property - 2 & ATS \\
\hline Availability of the alarm transmission path [\%] & 90.90 & 88.10 & - \\
\hline Availability of the alarm transmission system [\%] & - & - & 76.57 \\
\hline
\end{tabular}

port and USB port. The Jablonet pro is a specialized software enabling the management and development of alarm transmission systems. Thanks to its equipment it can cooperate with many different types of monitoring devices.

Many experimental measurements were necessary to obtain the reliable data on reliability of the transmission systems. As a part of the research into the reliability of alarm transmission systems, in the first phase of testing, measurements from the two different protected objects, in which no electrical security system was installed, were carried out. The measurements were carried out simultaneously for 10 days from both objects to simulate the real use of the system. The basis of the measurements was a testing device from which information was sent to the alarm transmission system center at regular 20-minute intervals about the intrusion of the protected object. In all the cases of this phase of experimental testing, it was the same type of alarm relay message in terms of size. The reason was regular switching of the alarm input of the communicator, to which the unified type of event that occurred during programming was set. Since this was the first stage of experimental testing, focused on the correct functionality of the test equipment, no restrictive conditions for the time of transmission of the message were defined. The first phase was aimed to find out whether the testing device can fully replace the control panel of the electric security system and thus simulate the protected object [8-9].

The ten-day interval was chosen because of the ability to modify the monthly availability formula. It was chosen to base the calculation on monthly availability because weekly availability is a verification calculation based on knowing annual availability. Since those were initial tests, information on the annual availability of the alarm transmission system could not have been provided.

Given the possibilities and focus of experimental testing, the two different protected objects were chosen, with different distances from the alarm transmission system center. The object - 1 was approximately 10 kilometers from the center of the alarm transmission system on the road and the air distance was approximately 6 kilometers. The object - 2 was approximately 16 kilometers from the center of the alarm transmission system on the road and the air distance was approximately 9 kilometers. In addition to different distances of the protected objects, there is also a difference in their location as the object - 1 is oriented to the southeast and object - 2 to the south of the alarm transmission system center. The center of the alarm transmission system is in the premises of the Science Park of the University of Zilina.

\section{$3 \quad$ Results}

Using the experimental tests, more than 1200 messages were transmitted from the protected object to the alarm transmission system center to determine the average value of the message time and availability of the alarm transmission system. As mentioned above, to express the availability of the alarm transmission system, the calculation for the monthly availability of the alarm transmission system was used, which is expressed according to the relation:

$$
M A=\left(1-\frac{S F}{43800}\right) * 100
$$

where:

$M A$ - monthly expression of the availability of the alarm transmission system expressed as a percentage,

$S F$ - the sum of breakdown times over 30 days, expressed in minutes,

43800 - the average number of minutes in one month except for a leap year.

Since in the pilot experimental tests measurements lasted only 10 days, the relation for calculation was adjusted. The adjustments consisted of changing the constant value of the average number of minutes per month from 43800 to 14600 , which is one-third, as the basis was on the SF parameter, which refers to a period of 30 days. Using the adjusted formula, it was found that the real availability of the alarm transmission system during the practical measurements was $76.57 \%$. The availability of the alarm transmission system is decisive for all the alarm transmission routes through which the protected objects are connected to the centralized security desk.

In evaluating the results of experimental testing, it was also decided to determine the availability of the alarm transmission path, i.e. one connected protected object. No attention was paid to this issue in terms of technical literature and technical legislation and standards. Therefore, a relationship was established allowing calculation of availability of the alarm transmission path, which is based on the issue of system reliability and looks as follows:

$A A T P=\left(1-\frac{N M}{M}\right) * 100$

where:

$A P P C$ - Availability of alarm transmission path,

$N M$ - Number of non-transmitted messages,

$M$ - Total number of messages.

Using Equation (2), availability of the alarm transmission path for each protected object was calculated 
separately. In the case of the protected object 1 , the availability of the alarm transmission path was $90.9 \%$ and in the case of the protected object $288.1 \%$. The experimental results obtained are also summarized in Table 2.

As can be seen from results in Table 2, the availability of the alarm transmission paths, as well as the alarm transmission system, is relatively low due to the short testing time. It was found as very difficult to compare them with the requirements of the technical standards of Table 1. The reason for the rather large distortion of the resulting data was the malfunction of the receiving device from day 8 until the end of experimental testing on day 10 . One could say that this is about $20 \%$ of all the data that affected the result. The reason for the malfunction was probably the absence of software used by the operator. The goal was to automate the whole process, so there was no interference with any part of the test. The equipment manufacturer was also informed of these findings, but no comment on the situation was possible to make, as this was a specific situation that could not occur under real conditions. The center of the alarm transmission system is a permanently operated workplace.

If, for example, on the second day of testing, the receiving device malfunctions, the availability value will be at a diametrically different level. In this case, it would not be possible to evaluate the testing. From this point of view, one can state that the ten-day cycle was suitably chosen to point out the possible shortcomings of the set requirements following the next phase of experimental testing.

\section{Discussion}

The need to test alarm systems has long been recognized in the circles of experts and scholars of literature and should be given due consideration. The importance of experimental tests affects many people, such as security managers, private security operators, installers, academics and, finally, end-users [10].

In addition to users of individual systems, the results of experimental tests are also needed for simulation programs designed to evaluate the proposed systems. Those results could influence design of the system at an early stage, focusing on design efficiency and cost-effectiveness of the solution [11-12].

Experimental testing was focused on an innovative way of testing alarm systems using the simple programmable circuits. Indeed, this type of testing can also be used for designing the critical infrastructure elements in different types of alarm systems. In addition to critical infrastructure, the results of experimental tests can be used to ensure the continuity of road traffic, particularly in the case of video surveillance systems testing against extreme weather conditions [13-14].

The results of the experimental tests can be understood from several perspectives as it is an overlap of industry interest. In terms of data transmission and capabilities, one can talk about the quality of the transmission service through a non-post channel. From the aforementioned definition of the availability of an alarm transmission system, it can be stated that it is precisely it from alarm transmission systems. In this statement one assumes that the whole testing methodology was designed and based on the issue of alarm transmission systems.

The ten-day cycle that this paper is dedicated to was the initial phase of testing that was needed to create the necessary image of the functionality of the whole, presented alarm transmission system and testing equipment. Currently, the second phase of testing is under way, which monitors the data transmission in the long term, while removing the identified shortcomings from the first phase. The data obtained so far are of a higher value in terms of value and the expected completion of the second phase is in February 2020.

Intruder alarm systems, video surveillance systems and alarm transmission systems have been tested at the Faculty of Security Engineering. In terms of the effectiveness of obtaining the data needed to evaluate the object protection system, it would be necessary to focus on experimental testing of the input control system and reliability of human factors to automate the object protection rating system even more accurately.

\section{Conclusion}

The paper is aimed to point out a new possibility of obtaining the data necessary to re-evaluate the system of object protection, which is formed by a combination of subsystems. The main topic was alarm systems, namely alarm transmission systems, in which the first experimental testing, focused on the availability of the transmission system using a testing device, was performed. When designing and creating the test equipment, the simple programmable circuits were used to simulate the connection of the protected object to the alarm transmission system center.

Using the long-term testing, 10 days, it was possible to determine the availability of the transmission system, as well as the alarm transmission path, with minimal attention to it. Experimental testing is based on the need to obtain the data needed for simulation programs to evaluate the object protection system. With selection of the alarm transmission systems, the long-term scientific intention of the Faculty of Security Engineering was followed upon, which, within its scientific and publishing activities, devotes itself to the evaluation of object protection systems comprehensively.

From individual parts of the object protection systems, it is necessary to pay due attention to experimental testing and to repeat it at regular intervals, focusing on analysis of the reliability development of individual end parts. From the comprehensive approach to evaluation of the object protection system, the representatives of the Faculty of Security Engineering will deal with the systems of access control. 


\section{References}

[1] BOROS, M., SISER, A., KEKOVIC, Z., MAZAL, J. Mechanical characteristics of cylinder pin tumbler locks as they relate to resistance testing. Communications - Scientific Letters of the University of Zilina [online]. 2018, 20(2), p. 96-101. ISSN 1335-4205, eISSN 2585-7878. Available from: http://komunikacie.uniza.sk/index.php/communications/article/ view/94

[2] KITTEL, L., LOVECEK, T. Passive protection elements breach resistance modeling. Communications - Scientific Letters of the University of Zilina [online]. 2011, 13(2), p. 53-58. ISSN 1335-4205, eISSN 2585-7878. Available from: http://komunikacie.uniza.sk/index.php/communications/article/view/820

[3] BOROS, M., LENKO, F. Possibility of transmission system disruption by intruder. In: 13th International Scientific Conference on Sustainable, Modern and Safe Transport, TRANSCOM 2019 : proceedings [online]. 2019. ISSN 2352-1457. Available from: https://doi.org/10.1016/j.trpro.2019.07.176

[4] GUTTEN, M., JANURA, R., SEBOK, M., KORENCIAK, D., KUCERA, M. Measurement of short-circuit effects on transformer winding with SFRA method and impact test. Metrology and Measurement Systems [online]. 2016, 23(4), p. 521-529. ISSN 0860-8229. Available from: https://doi.org/10.1515/mms-2016-0044

[5] KUTAJ, M., JASENCAK, L., VELAS, A., BOROS, M. The design of a testing device for passive infrared motion detectors. WIT Transactions on The Built Environment, Safety and Security Engineering VII [online]. 2018, 174, p. 457-463. eISSN 1743-3509. Available from: https://doi.org/10.2495/SAFE170411

[6] VELAS, A., KUTAJ, M., DUROVEC, M. Influence of changing the parameters of the camera system on video-based motion detection. In: International Carnahan Conference on Security Technology ICCST 2017 : proceedings [online]. 2017, ISSN 1071-6572. Available from: https://doi.org/10.1109/CCST.2017.8167829

[7] MOZER, V., LOVECEK, T., VELAS, A., MAKOVICKA, L. Fire safety and security threats identification and elimination. Advanced Materials Research [online]. 2014, 1001, p. 306-311. ISSN 1022-6680. Available from: https://doi.org/10.4028/www.scientific.net/AMR.1001.306

[8] VELAS, A., LOVECEK, T., VALOUCH, J., DWORZECKI, J., VNENCAKOVA, E. Testing radio signal range of selected components. Communications - Scientific Letters of the University of Zilina [online]. 2018, 20(2), p.. 68-77. ISSN 1335-4205, eISSN 2585-7878. Available from: http://komunikacie.uniza.sk/index.php/communications/article/view/90

[9] URBANCOKOVA, H., KOVAR, S., HALASKA, O., VALOUCH, J., POSPISILIK, M. Conditions for testing effects of radiofrequency electromagnetic fields on electronic device. WSEAS Transactions on Environment and Development. 2018, 14, p. 145-152. ISSN 1790-5079, eISSN 2224-3496.

[10] LOVECEK, T. Present and future ways of physical property protection. Communications - Scientific Letters of the University of Zilina [online]. 2008, 10(1), p. 35-39. ISSN 1335-4205, eISSN 2585-7878. Available from: http://komunikacie.uniza.sk/index.php/communications/article/view/1028

[11] RISTVEJ, J., ONDREJKA, R., SIMAK, L., LOVECEK, T., HOLLA, K., LACINAK, M., SURINOVA, L., JANOSIKOVA, M. Simulation technologies in risk prevention within crisis management. In: 30th European Simulation and Modelling Conference ESM 2016 : proceedings. 2016, ISBN 978-907738195-3.

[12] KUBAS, J., SOLTES, V., MISIK, J., STOFKOVA, Z. Efficiency of using financial resources and their impact on security in a local context. In: 12th International Scientific Conference of Young Scientists on Sustainable, Modern and Safe Transport TRANSCOM 2017 : proceedings [online]. 2017, ISSN 1877-7058. Available from: https://doi.org/10.1016/j. proeng.2017.06.086

[13] SOLTES, V., KUBAS, J., STOFKOVA, Z. The safety of citizens in road transport as a factor of quality of life. In: 22nd International Scientific on Conference Transport Means : proceedings. 2018, ISSN: 1822-296X.

[14] LOVECEK, T., SISER, A., MARIS, L. Use case of waterwork physical protection system robustness evaluation as a part of Slovak critical infrastructure. In: International Carnahan Conference on Security Technology ICCST 2017 : proceedings [online]. 2017, ISSN 10716572. Available from: https://doi.org/10.1109/CCST.2017.8167811 